\title{
Serum microRNA expression profiling in patients with multiple system atrophy
}

\author{
KODAI KUME ${ }^{1,2}$, HISAKAZU IWAMA ${ }^{3}$, KAZUSHI DEGUCHI ${ }^{1,4}$, KAZUYO IKEDA $^{4}$, \\ TADAYUKI TAKATA ${ }^{4}$, YOHEI KOKUDO ${ }^{5}$, MASAKI KAMADA ${ }^{5}$, KEIKO FUJIKAWA ${ }^{4}$, \\ KAYO HIROSE ${ }^{4}$, HISASHI MASUGATA ${ }^{2}$, TETSUO TOUGE ${ }^{6}$ and TSUTOMU MASAKI $^{4}$ \\ ${ }^{1}$ Department of Neurology, Kagawa University Hospital; ${ }^{2}$ Department of Integrated Medicine; \\ ${ }^{3}$ Life Science Research Center; Departments of ${ }^{4}$ Gastroenterology and Neurology, ${ }^{5}$ Intractable Neurological \\ Research and ${ }^{6}$ Health Sciences, Faculty of Medicine, Kagawa University, Kita-gun, Kagawa 761-0793, Japan
}

Received May 15, 2016; Accepted April 26, 2017

DOI: $10.3892 / \mathrm{mmr} .2017 .7995$

\begin{abstract}
Multiple system atrophy (MSA) is a sporadic neurodegenerative disease that is pathologically characterized by $\alpha$-synuclein positive glial cytoplasmic inclusions in oligodendrocytes. The clinical diagnosis of MSA is often challenging as there are no established biomarkers and diagnoses are now based on clinical findings alone. At present, the etiology and pathogenesis of MSA are unclear. It has been reported that dysregulation of microRNA (miRNA/miR) serves an important role in neurodegenerative disorders including Alzheimer's disease, Parkinson's disease and amyotrophic lateral sclerosis. The miRNA profile of patients with MSA remains to be established. The present study investigated the serum miRNA expression level of 10 patients with MSA, using microarray chips including 668 miRNAs. It was identified that 50 miRNAs were significantly upregulated and 17 miRNAs were significantly downregulated in the serum of the patients with MSA. The most upregulated miRNA was miR-16, which may induce the accumulation of $\alpha$-synuclein. The target genes of some miRNAs upregulated in MSA (including miR-17, 20a, 24, 25, 30d and 451) were associated with autophagy-associated molecules. The present study concluded that the expression pattern of miRNAs may be a clinical biomarker for MSA and targeting these miRNAs may provide a novel treatment for MSA.
\end{abstract}

Correspondence to: Professor Tsutomu Masaki, Department of Gastroenterology and Neurology, Faculty of Medicine, Kagawa University, 1750-1 Ikenobe, Miki-cho, Kita-gun, Kagawa 761-0793, Japan

E-mail: tmasaki@med.kagawa-u.ac.jp

Key words: multiple system atrophy, microRNA, microRNA-16, $\alpha$-synuclein, autophagy

\section{Introduction}

Multiple system atrophy (MSA) is a sporadic neurodegenerative disorder characterized by a combination of various degrees of parkinsonism, cerebellar ataxia and autonomic dysfunction (1). At present, there are no established biomarkers of MSA and so the clinical diagnosis of MSA is dependent on the assessment of clinical symptoms, thus misdiagnoses are frequent (2). The characteristic pathological hallmark of MSA is the accumulation of $\alpha$-synuclein positive glial cytoplasmic inclusions in oligodendrocytes (3). The pathogenesis of MSA remains unclear, although it has been reported that $\alpha$-synuclein accumulation serves a key role in neurodegeneration $(3,4)$.

microRNA (miRNA) are short RNA molecules that function as post-transcriptional regulators that bind to complementary sequences on target mRNA transcripts, typically resulting in translational repression or target degradation and gene silencing (5). Previous studies have demonstrated that the dysregulation of miRNA serves an important role in a number of neurological disorders, including Alzheimer's disease, Parkinson's disease (PD) (6) and amyotrophic lateral sclerosis (7). However, the miRNA profile of patients with MSA remains to be fully investigated.

Increased serum levels of insulin like growth factor (IGF)-1 have been reported in patients with MSA $(8,9)$. Since IGF-1 signaling has been revealed to be regulated by several miRNAs $(10,11)$, it may be hypothesized that miRNAs and IGF-1 contribute to the pathogenesis of MSA.

In the present study, the expression of serum miRNAs and IGF-1 was investigated in patients with MSA, in order to identify potential biomarkers and clarify the pathogenesis of MSA.

\section{Materials and methods}

Patients and samples. A total of 10 patients with MSA ( 7 males and 3 females; mean age, $64 \pm 6.9$ years; range, 49-75 years) and 6 age- and sex-matched healthy controls (caregivers of the MSA patients without MSA; 4 males and 2 females; mean age, 64 \pm 2.9 ; range, 58-66 years) were recruited for the present study between January and December 2013, from the Department of Neurology, Kagawa 
University Hospital. All of the patients with MSA were diagnosed according to the 2008 consensus statement on the diagnosis of MSA: Definite, 1 patient; probable, 4 patients; possible, 5 patients (12). Five of the 10 patients had MSA of the parkinsonian form (MSA-P), and the other 5 patients had MSA of the cerebellar form (MSA-C). The mean duration of the illness was $5.5 \pm 2.8$ years (Table I). Blood samples were harvested upon recruitment and processed for serum isolation within $2 \mathrm{~h}$ following withdrawal. Whole blood was centrifuged at $1,500 \mathrm{xg}$ for $15 \mathrm{~min}$ at $4^{\circ} \mathrm{C}$. Each serum sample was divided into aliquots and stored at $-80^{\circ} \mathrm{C}$ until analysis. Informed consent was obtained from all of the participants and the present study was approved by the Ethics Committee of Kagawa University (Kagawa, Japan).

RNA isolation. Total RNA was extracted from the serum samples using an miRNeasy Mini kit (Qiagen, Inc., Valencia, CA, USA) according to the manufacturer's instructions. All RNA samples used in the present study exhibited A260/280 ratios between 2.0 and 2.1. The integrity of RNA was determined using a NanoDrop 2000 spectrophotometer (Thermo Fisher Scientific, Inc., Waltham, MA, USA). The quality of total RNA was determined using the RNA Nano 6000 chips from the Agilent 2100 Bioanalyzer (Agilent Technologies, Inc., Santa Clara, CA, USA) according to the manufacturer's protocol, and all RNA samples used for the microarray analyses had RNA Integrity Number values $>8.2$. Briefly, total RNA from all serum samples was heated at $70^{\circ} \mathrm{C}$ for $2 \mathrm{~min}$ and incubated on ice for $5 \mathrm{~min}$. Subsequently, samples (1 $\mu \mathrm{l}$ ) were loaded into each lane on the RNA Nano 6000 chips, and the bands of $18 \mathrm{~S}$ (arrow) and 28S ribosomal RNA (arrowhead) in the gel were detected using the Agilent 2100 Bioanalyzer (Fig. 1A). These RNA samples were stored at $-80^{\circ} \mathrm{C}$.

miRNA arrays. Total RNA was labeled with Hy3 dye using an miRCURY LNA microRNA Array Hi-Power Labeling kit (Exiqon A/S, Vedbæk, Denmark). Total RNA (2 $\mu \mathrm{g})$ was incubated with a spike of $30 \mathrm{~min}$ at $37^{\circ} \mathrm{C}$ and then at $95^{\circ} \mathrm{C}$ for $5 \mathrm{~min}$. Hy 3 dye and Hi-Power Labeling enzyme were then added to each sample. The enzyme was then heat-inactivated at $16^{\circ} \mathrm{C}$ for $1 \mathrm{~h}$ and at $65^{\circ} \mathrm{C}$ for $15 \mathrm{~min}$, protected from light. The samples were loaded onto the arrays by capillary force using 3D-Gene miRNA oligo chips (version 17; Toray Industries, Inc., Tokyo, Japan). The chips enabled the examination of the expression of 679 miRNAs printed in duplicate spots.

The arrays were incubated at $32^{\circ} \mathrm{C}$ for $16 \mathrm{~h}$, then briefly washed in a $30^{\circ} \mathrm{C}$ wash buffer solution $[0.5 \mathrm{X}$ saline-sodium citrate (SSC), $0.1 \% \mathrm{SDS}$, rinsed in wash buffer solution (0.2X SSC, $0.1 \%$ SDS) and then washed again in another buffer solution (0.05X SSC), according to the manufacturer's instructions (Toray Industries, Inc.). The arrays were centrifuged for $1 \mathrm{~min}$ at $600 \mathrm{x} \mathrm{g}$ at room temperature for drying, followed by immediate scanning using a 3D-Gene 3000 miRNA microarray scanner (Toray Industries, Inc.). It was calculated that the relative expression level of each miRNA by comparing the average signal intensities of the valid spots with their mean value throughout the microarray experiments, following normalization to their adjusted median values.
Quantification of miRNA. Isolation of RNA was performed using a miRNeasy serum/plasma kit adding spike in control cel-miR-39 (Qiagen, Inc.), according to the manufacturer's protocol. cDNA was individually synthesized for each target miRNA using miRNA Reverse Transcription kit (Thermo Fisher Scientific, Inc.) according to the manufacturer's protocol. The detection of miRNA expression was performed by reverse transcription-quantitative polymerase chain reaction (RT-qPCR), using TaqMan miRNA Assays and TaqMan Universal Master MixII (Thermo Fisher Scientific, Inc.) according to the manufacturer's protocol. Thermocycling conditions were as follows: Initial denaturation at $95^{\circ} \mathrm{C}$ for $10 \mathrm{~min}$, followed by 40 cycles at $95^{\circ} \mathrm{C}$ for $15 \mathrm{sec}$ and at $60^{\circ} \mathrm{C}$ for $60 \mathrm{sec}$. The relative expression levels of miRNA were calculated using the comparative $\mathrm{Cq}$ method (13) and normalized to cel-miR-39 expression. Experiments were performed in triplicate.

Heatmap. A heatmap was created using $\mathrm{R}$ software version 3.2.3 (https://www.R-project.org) in which the expression levels of miRNAs from each of the 10 MSA patients and 6 healthy controls were represented using unsupervised hierarchical clustering Brunner-Munzel analysis. The heatmap was color-coded according to the $\log 2$-transformed expression levels. The center level of the color code is set as the median value over all of the values used in the heatmap. White color represented mean values, red indicated an increase and blue represented a decrease in expression.

Measurement of IGF-1. Serum IGF-1 levels were measured by Shikoku Chuken (Ayagawa, Japan) using an immunoradiometric assay.

Statistical analysis. Data are expressed as the mean \pm standard deviation. The statistical significance of the differences between groups was assessed using unpaired Student's t-test. $\mathrm{P}<0.05$ was considered to indicate a statistically significant difference. Statistical analysis was performed using SPSS software version 23.0 (IBM Corp., Armonk, NY, USA).

\section{Results}

Identification of differentially expressed plasma miRNA in the patients with MSA and healthy controls. The miRNA expression levels in serum obtained from the patients with MSA and healthy controls were compared. The custom microarray platform identified 50 miRNAs that were upregulated and 17 miRNAs that were downregulated in the serum of the patients with MSA (Table II). As shown in Fig. 1B, the representative upregulated miRNAs were: miR-16 (spot no. 1), miR-223 (spot no. 2), miR-25 (spot no. 3), let-7c (spot no. 4), miR-17 (spot no. 5), let-7d (spot no. 6), let-7i (spot no. 7), let-7b (spot no. 8), miR-24 (spot no. 9), let-7a (spot no. 10) and miR-20a (spot no. 11). An unsupervised hierarchical clustering analysis using a Brunner-Munzel test revealed that the patients with MSA clustered separately from the healthy control group (Fig. 2).

Identification of differentially expressed plasma miRNA in the MSA-P and MSA-C patients. The miRNA expression 
Table I. Profiles of patients with MSA-P and -C.

\begin{tabular}{cccccc}
\hline Patient number & Age (years) & Sex & Subtype & Diagnostic criteria & Disease duration (years) \\
\hline 1 & 59 & M & P & Possible & 3 \\
2 & 64 & M & C & Probable & 5 \\
3 & 69 & M & C & Possible & 3 \\
4 & 64 & M & C & Probable & 7 \\
5 & 63 & M & P & Definite & 8 \\
6 & 75 & F & P & Probable & 9 \\
7 & 62 & F & C & Probable & 3 \\
8 & 66 & M & P & Probable & 5 \\
9 & 69 & C & C & Possible & 2 \\
10 & 49 & F & P & Possible &
\end{tabular}

Diagnostic criteria, all of the patients with MSA were diagnosed according to the 2008 consensus statement on the diagnosis of MSA (8). MSA, multiple system atrophy; P, parkinsonian form of MSA; C, cerebellar form of MSA; M, male; F, female.
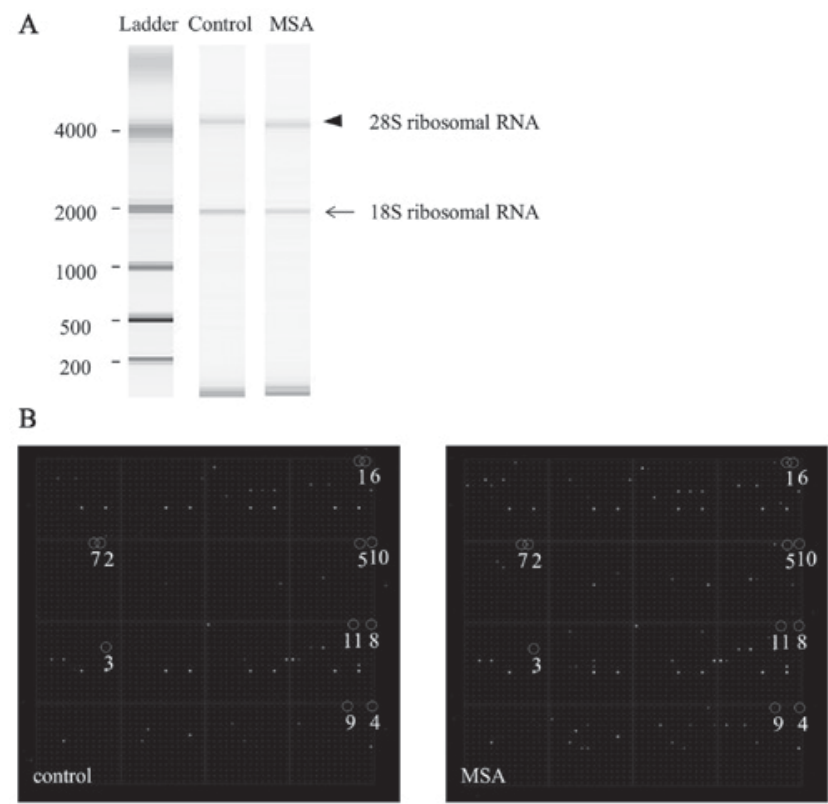

Figure 1. Quality of total RNA and miRNA expression in the serum of a typical patient with MSA. (A) The bands of 18S (arrow) and 28S (arrowhead) ribosomal RNA in the gel were detected using a 2100 Bioanalyzer. (B) Representative miRNA expression in control and MSA cases, using miRNA chip analysis. Spot numbers 1 to 11 are presented: 1, miR-16; 2, miR-223; 3, miR-25; 4, let-7c; 5, miR-17; 6, let-7d; 7, let-7i; 8, let-7b; 9, miR-24; 10, let-7a; 11, miR-20a. MSA, multiple system atrophy; miRNA/miR, microRNA.

levels in serum obtained from the MSA-P and MSA-C patients were then compared. This analysis identified that 22 miRNAs were upregulated and 17 miRNAs were downregulated in the serum of the patients with MSA-P (Table III). An unsupervised hierarchical clustering analysis using a Brunner-Munzel test demonstrated that the MSA-P patients clustered separately from the MSA-C patients (Fig. 3).

Quantification of miR-16 and miR-223. The expression levels of miR-16 and miR-223 were determined using RT-qPCR to

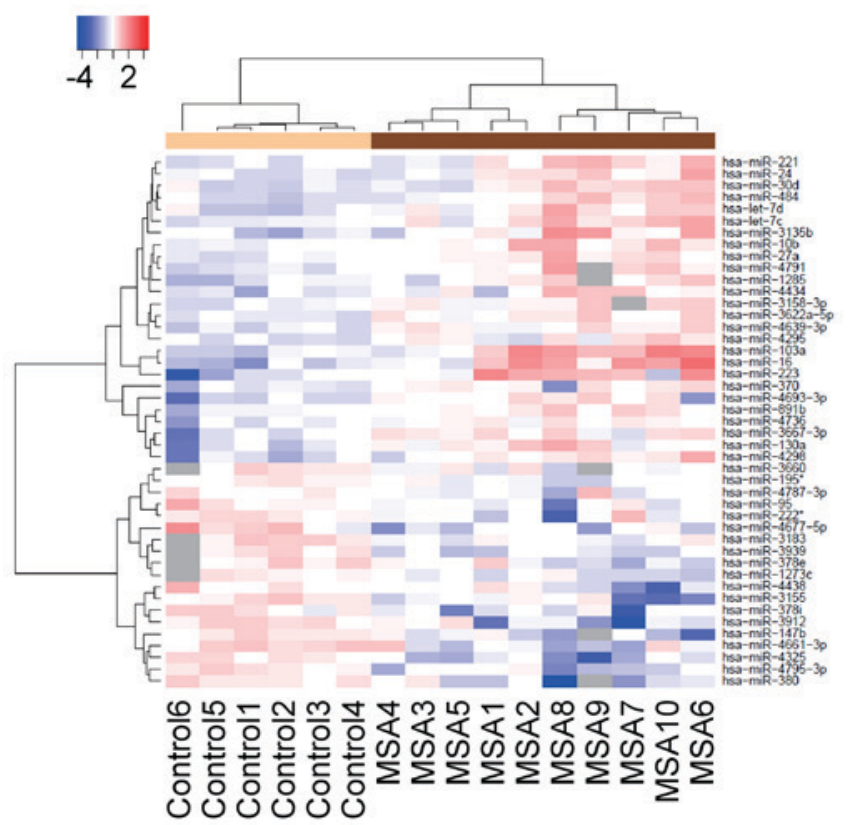

Figure 2. Hierarchical clustering of miRNAs from the healthy controls and patients with MSA. Samples are arranged in columns and miRNAs in rows. The miRNA clustering tree is presented on the left, and the sample clustering tree is present at the top of each heat map. Heat maps depict the relative expression intensity for each miRNA in which the base-2 logarithm of the intensity is median-centered for each row. The color coding is indicated as a horizontal bar. MSA, multiple system atrophy; miRNA, microRNA.

validate the miRNA array data. The mean $\Delta \mathrm{Cq} \pm$ standard deviation of miR-16 was $3.6 \pm 1.1$ and $3.2 \pm 1.4$ for the control and MSA groups, respectively (Fig. 4A). Similarly, for miR-223, the value was $2.3 \pm 1.1$ and $2.0 \pm 1.4$ for the control and MSA groups (Fig. 4B). There were no significant differences between the miRNA levels of the patients with MSA and the healthy controls.

Quantification of IGF-1. Mean serum IGF-1 levels were revealed to be $68.1 \pm 34.2 \mathrm{ng} / \mathrm{ml}$ in control group and $105 \pm 42.1 \mathrm{ng} / \mathrm{ml}$ in the MSA group (Fig. 4C). However, no 
Table II. Statistical results and chromosomal locations of miRNAs in the 10 patients with MSA and 6 healthy controls.

\begin{tabular}{|c|c|c|c|}
\hline miRNA & Fold change (MSA/control) & P-value & Chromosomal localization \\
\hline \multicolumn{4}{|l|}{ Upregulated } \\
\hline hsa-miR-16 & 4.42 & 0.009 & $13 q 14.2$ \\
\hline hsa-miR-451 & 4.21 & 0.017 & $17 \mathrm{q} 11.2$ \\
\hline hsa-miR-103a & 3.43 & 0.006 & $5 q 34$ \\
\hline hsa-miR-223 & 3.28 & 0.007 & $\mathrm{Xq} 12$ \\
\hline hsa-miR-486-5p & 2.70 & 0.023 & $8 \mathrm{p} 11.21$ \\
\hline hsa-miR-107 & 2.45 & 0.014 & $10 \mathrm{q} 23.31$ \\
\hline hsa-miR-25 & 2.42 & 0.029 & 7q22.1 \\
\hline hsa-miR-3135b & 2.31 & 0.035 & 6 \\
\hline hsa-miR-15b & 2.19 & 0.009 & $3 q 25.33$ \\
\hline hsa-miR-185 & 2.14 & 0.010 & $22 q 11.21$ \\
\hline hsa-miR-939 & 2.09 & 0.048 & $8 \mathrm{q} 24.3$ \\
\hline hsa-miR-92a & 2.08 & 0.036 & $13 q 31.3$ \\
\hline hsa-miR-4298 & 2.07 & 0.006 & 11 \\
\hline hsa-miR-92b & 2.07 & 0.019 & $1 \mathrm{q} 22$ \\
\hline hsa-let-7c & 2.02 & 0.006 & $21 q 21.1$ \\
\hline hsa-miR-17 & 1.97 & 0.007 & $13 q 31.3$ \\
\hline hsa-miR-4693-3p & 1.95 & 0.005 & 11 \\
\hline hsa-miR-130a & 1.95 & 0.010 & $5 q 34$ \\
\hline hsa-let-7d & 1.91 & 0.012 & $9 q 22.32$ \\
\hline hsa-let-7i & 1.91 & 0.003 & $12 \mathrm{q} 14.1$ \\
\hline hsa-miR-484 & 1.90 & 0.004 & $16 \mathrm{p} 13.11$ \\
\hline hsa-miR-4791 & 1.89 & 0.019 & 3 \\
\hline hsa-miR-522 & 1.88 & 0.003 & $19 q 13.42$ \\
\hline hsa-miR-26a & 1.88 & 0.033 & 3 p22.2 \\
\hline hsa-let-7b & 1.86 & 0.024 & $22 q 13.31$ \\
\hline hsa-miR-3605-3p & 1.86 & 0.009 & 1 \\
\hline hsa-miR-30d & 1.83 & 0.006 & $8 q 24.22$ \\
\hline hsa-miR-4434 & 1.80 & 0.016 & 2 \\
\hline hsa-miR-4281 & 1.80 & 0.007 & 5 \\
\hline hsa-miR-106a & 1.76 & 0.015 & $\mathrm{Xq} 26.2$ \\
\hline hsa-miR-3667-3p & 1.74 & 0.008 & 22 \\
\hline hsa-miR-99a & 1.74 & 0.040 & $21 q 21.1$ \\
\hline hsa-miR-24 & 1.74 & 0.017 & $9 q 22.32$ \\
\hline hsa-miR-221 & 1.73 & 0.020 & Xp11.3 \\
\hline hsa-miR-31 & 1.73 & 0.024 & $9 p 21.3$ \\
\hline hsa-miR-1285 & 1.73 & 0.007 & $7 q 21-q 22$ \\
\hline hsa-miR-218-2 & 1.70 & 0.041 & $5 q 34$ \\
\hline hsa-let-7a & 1.70 & 0.025 & $9 q 22.32$ \\
\hline hsa-miR-27a & 1.68 & 0.019 & $19 \mathrm{p} 13.13$ \\
\hline hsa-miR-20a & 1.68 & 0.015 & $13 \mathrm{q} 31.3$ \\
\hline hsa-miR-518a-3p & 1.67 & 0.043 & $19 q 13.42$ \\
\hline hsa-miR-19b & 1.67 & 0.028 & $13 q 31.3$ \\
\hline hsa-miR-10b & 1.67 & 0.028 & 2q31.1 \\
\hline hsa-miR-377 & 1.66 & 0.015 & $14 q 32.31$ \\
\hline hsa-miR-4698 & 1.65 & 0.033 & 12 \\
\hline hsa-miR-186 & 1.65 & 0.042 & 1p31.1 \\
\hline hsa-miR-126 & 1.64 & 0.032 & $9 q 34.3$ \\
\hline hsa-miR-1303 & 1.61 & 0.032 & 5 \\
\hline hsa-miR-500b & 1.61 & 0.029 & Xp11.23 \\
\hline hsa-miR-3622a-5p & 1.61 & 0.002 & 8 \\
\hline hsa-miR-3139 & 0.50 & 0.037 & 4 \\
\hline
\end{tabular}


Table II. Continued.

\begin{tabular}{|c|c|c|c|}
\hline miRNA & Fold change (MSA/control) & P-value & Chromosomal localization \\
\hline \multicolumn{4}{|l|}{ Downregulated } \\
\hline hsa-miR-4325 & 0.46 & 0.0003 & 20 \\
\hline hsa-miR-380 & 0.50 & 0.0008 & $14 q 32.31$ \\
\hline hsa-miR-3912 & 0.51 & 0.0019 & 5 \\
\hline hsa-miR-4661-3p & 0.54 & 0.0032 & 8 \\
\hline hsa-miR-4795-3p & 0.55 & 0.0038 & 3 \\
\hline hsa-miR-4458 & 0.55 & 0.041 & $5 p 15.31$ \\
\hline hsa-miR-3155 & 0.55 & 0.0082 & 10 \\
\hline hsa-miR-590-3p & 0.55 & 0.045 & $7 q 11.23$ \\
\hline hsa-miR-147b & 0.56 & 0.0034 & $15 \mathrm{q} 21.1$ \\
\hline hsa-miR-4439 & 0.56 & 0.046 & 2 \\
\hline hsa-miR-378i & 0.56 & 0.016 & 22 \\
\hline hsa-miR-3939 & 0.57 & 0.0058 & 6 \\
\hline hsa-miR-4495 & 0.58 & 0.026 & 12 \\
\hline hsa-miR-526b & 0.58 & 0.036 & $19 q 13.42$ \\
\hline hsa-miR-548z & 0.58 & 0.041 & 12 \\
\hline hsa-miR-3183 & 0.59 & 0.0082 & 17 \\
\hline
\end{tabular}

miRNA/miR, microRNA; MSA, multiple system atrophy; hsa, human (Homo sapiens).

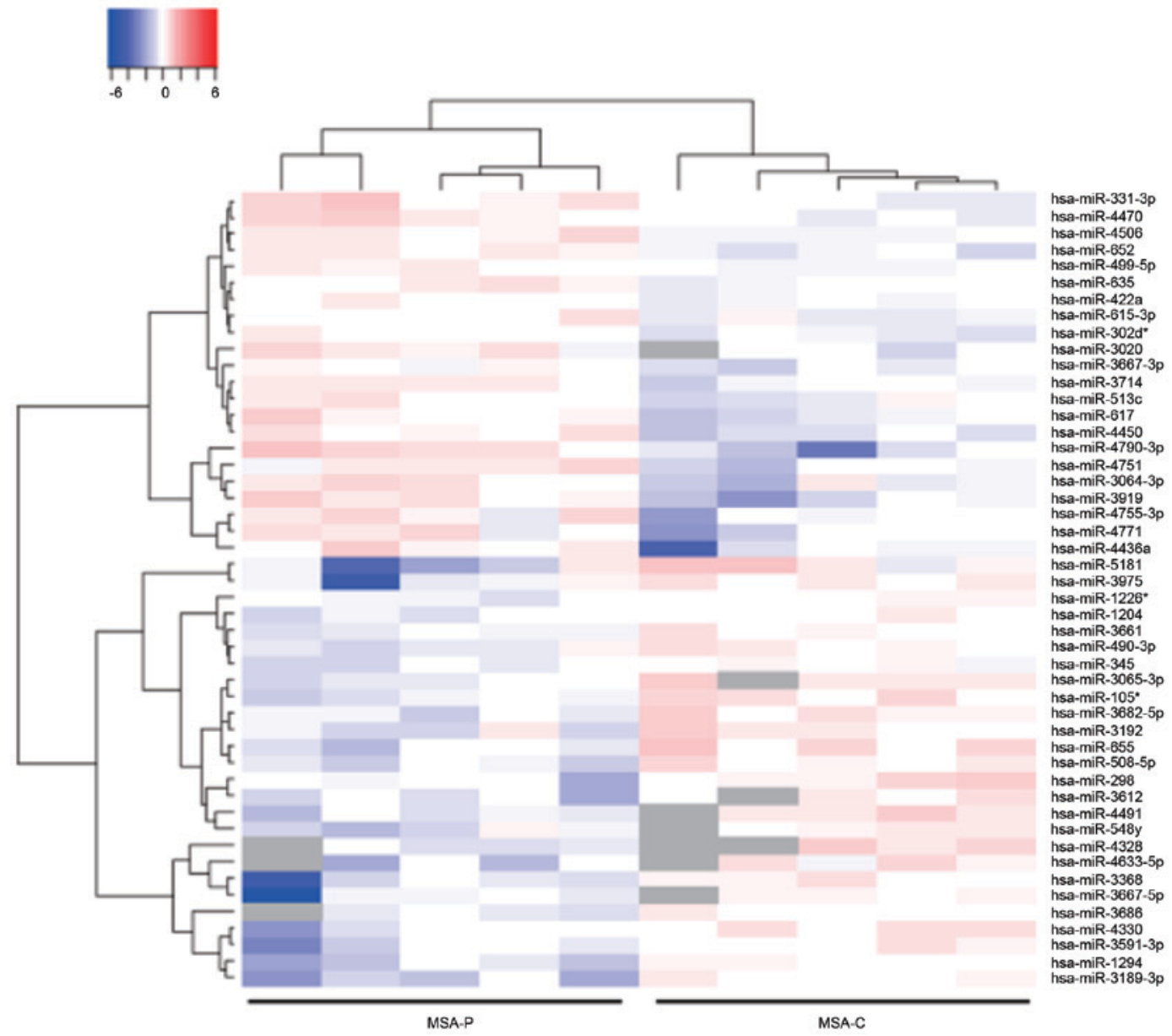

Figure 3. Hierarchical clustering of miRNAs from the MSA-P and MSA-C patients. Samples are arranged in columns and miRNAs in rows. The miRNA clustering tree is shown on the left, and the sample clustering tree is shown at the top of each heat map. Heat maps depict the relative expression intensity for each miRNA in which the base-2 logarithm of the intensity is median-centered for each row. The color coding is indicated as a horizontal bar. MSA, multiple system atrophy; MSA-P, parkinsonian MSA; MSA-C, cerebellar MSA; miRNA, microRNA. 
Table III. Statistical results and chromosomal locations of miRNAs in the patients with MSA-P and -C.

\begin{tabular}{|c|c|c|c|}
\hline miRNA & Fold change (MSA-P/-C) & P-value & Chromosomal localization \\
\hline \multicolumn{4}{|l|}{ Upregulated } \\
\hline hsa-miR-4790-3p & 3 & 0.0016 & $3 \mathrm{p} 26.1$ \\
\hline hsa-miR-3919 & 2.31 & 0.015 & $3 q 25.32$ \\
\hline hsa-miR-4436a & 2 & 0.025 & 2p11.2 \\
\hline hsa-miR-3202 & 1.97 & 0.027 & $\mathrm{Xq} 28$ \\
\hline hsa-miR-4450 & 1.95 & 0.0014 & $4 q 21.1$ \\
\hline hsa-miR-4771 & 1.9 & 0.032 & $2 \mathrm{p} 11.2$ \\
\hline hsa-miR-331-3p & 1.89 & 0.021 & $12 q 22$ \\
\hline hsa-miR-3064-3p & 1.87 & 0.033 & $17 q 23.3$ \\
\hline hsa-miR-4751 & 1.87 & 0.019 & $19 q 13.33$ \\
\hline hsa-miR-617 & 1.82 & 0.03 & $12 \mathrm{q} 21.31$ \\
\hline hsa-miR-4470 & 1.8 & 0.014 & $8 q 12.3$ \\
\hline hsa-miR-4755-3p & 1.76 & 0.045 & $20 q 11.22$ \\
\hline hsa-miR-379 & 1.75 & 0.048 & $14 q 32.31$ \\
\hline hsa-miR-3714 & 1.7 & 0.001 & $3 \mathrm{p} 24.3$ \\
\hline hsa-miR-4506 & 1.69 & 0.0032 & $14 q 32.12$ \\
\hline hsa-miR-454 & 1.68 & 0.035 & $17 q 22$ \\
\hline hsa-miR-135a & 1.66 & 0.038 & $3 \mathrm{p} 21.2$ \\
\hline hsa-miR-652 & 1.61 & 0.007 & $\mathrm{Xq} 23$ \\
\hline hsa-miR-4790-3p & 3 & 0.0016 & $3 \mathrm{p} 26.1$ \\
\hline hsa-miR-3919 & 2.31 & 0.015 & $3 q 25.32$ \\
\hline hsa-miR-4436a & 2 & 0.025 & $2 \mathrm{p} 11.2$ \\
\hline hsa-miR-3202 & 1.97 & 0.027 & $\mathrm{Xq} 28$ \\
\hline \multicolumn{4}{|l|}{ Downregulated } \\
\hline hsa-miR-518f & 0.37 & 0.041 & $19 q 13.42$ \\
\hline hsa-miR-4703-5p & 0.41 & 0.043 & $13 q 14.3$ \\
\hline hsa-miR-3189-3p & 0.44 & 0.008 & $19 \mathrm{p} 13.11$ \\
\hline hsa-miR-655 & 0.46 & 0.017 & $14 q 32.31$ \\
\hline hsa-miR-3168 & 0.5 & 0.015 & $13 q 14.11$ \\
\hline hsa-miR-105 & 0.51 & 0.014 & Xq28 \\
\hline hsa-miR-1294 & 0.53 & 0.011 & $5 q 33.2$ \\
\hline hsa-miR-3686 & 0.53 & 0.019 & $8 q 24.21$ \\
\hline hsa-miR-4330 & 0.53 & 0.012 & $\mathrm{Xq} 28$ \\
\hline hsa-miR-508-5p & 0.53 & 0.014 & $\mathrm{Xq} 27.3$ \\
\hline hsa-miR-3591-3p & 0.53 & 0.027 & $18 \mathrm{q} 21.31$ \\
\hline hsa-miR-298 & 0.54 & 0.042 & 20q13.32 \\
\hline hsa-miR-3682-5p & 0.54 & 0.032 & 2p16.2 \\
\hline hsa-miR-3115 & 0.55 & 0.046 & 1p36.12 \\
\hline hsa-miR-3192 & 0.55 & 0.035 & 20p11.23 \\
\hline hsa-miR-3975 & 0.55 & 0.037 & $18 q 12.2$ \\
\hline hsa-miR-518f & 0.37 & 0.041 & $19 q 13.42$ \\
\hline
\end{tabular}

miRNA/miR, microRNA; MSA, multiple system atrophy; P, parkinsonian form of MSA; C, cerebellar form of MSA; hsa, human (Homo sapiens).

statistically significant difference in IGF-1 levels was detected between patients with MSA and healthy controls.

\section{Discussion}

In the present study, 50 upregulated miRNAs and 17 downregulated miRNAs were identified in serum from patients with
MSA, using a microarray platform. The hierarchical clustering analysis identified marked differences between the miRNA profiles of the MSA and the control groups.

There are few reports on miRNA profiling in patients with MSA $(14,15)$. It has been demonstrated that miR-24, miR-223 and miR-324-3p are upregulated in the serum of patients with MSA or PD (14), and a greater upregulation of 
Table IV. miRNAs and target genes associated with autophagy.

\begin{tabular}{|c|c|c|c|}
\hline Author, year & miRNA & Target gene & (Refs.) \\
\hline Kawamoto et al, 2007 & $\operatorname{miR}-24$ & ATG4 & $(20)$ \\
\hline Pan et al, 2015 & $\operatorname{miR}-17$ & ATG7 & $(21)$ \\
\hline $\begin{array}{l}\text { Comincini et al, } 2013 \text {; } \\
\text { Sun et al, 2015; } \\
\text { Wang et al, } 2015\end{array}$ & $\operatorname{miR}-20 a$ & ULK1, LC3-II, ATG16L1 & $(22,23,25$ \\
\hline Wu et al, 2012 & $\operatorname{miR}-25$ & ULK1 & $(24)$ \\
\hline $\begin{array}{l}\text { Wang et al, 2015; } \\
\text { Yang et al, } 2013\end{array}$ & miR-30d & Beclin-1, BNIP3L, ATG2, ATG5, ATG12 & $(25,26)$ \\
\hline Zhang et al, 2014 & $\operatorname{miR}-451$ & TSC1 & $(27)$ \\
\hline
\end{tabular}

miRNA/miR, microRNA; ATG, autophagy-related; ULK, Unc-51 like autophagy activating kinase; LC3, microtubule-associated protein 1A/1B-light chain 3; BNIP3L, BCL2 interacting protein 3 like; TSC1, tuberous sclerosis 1.
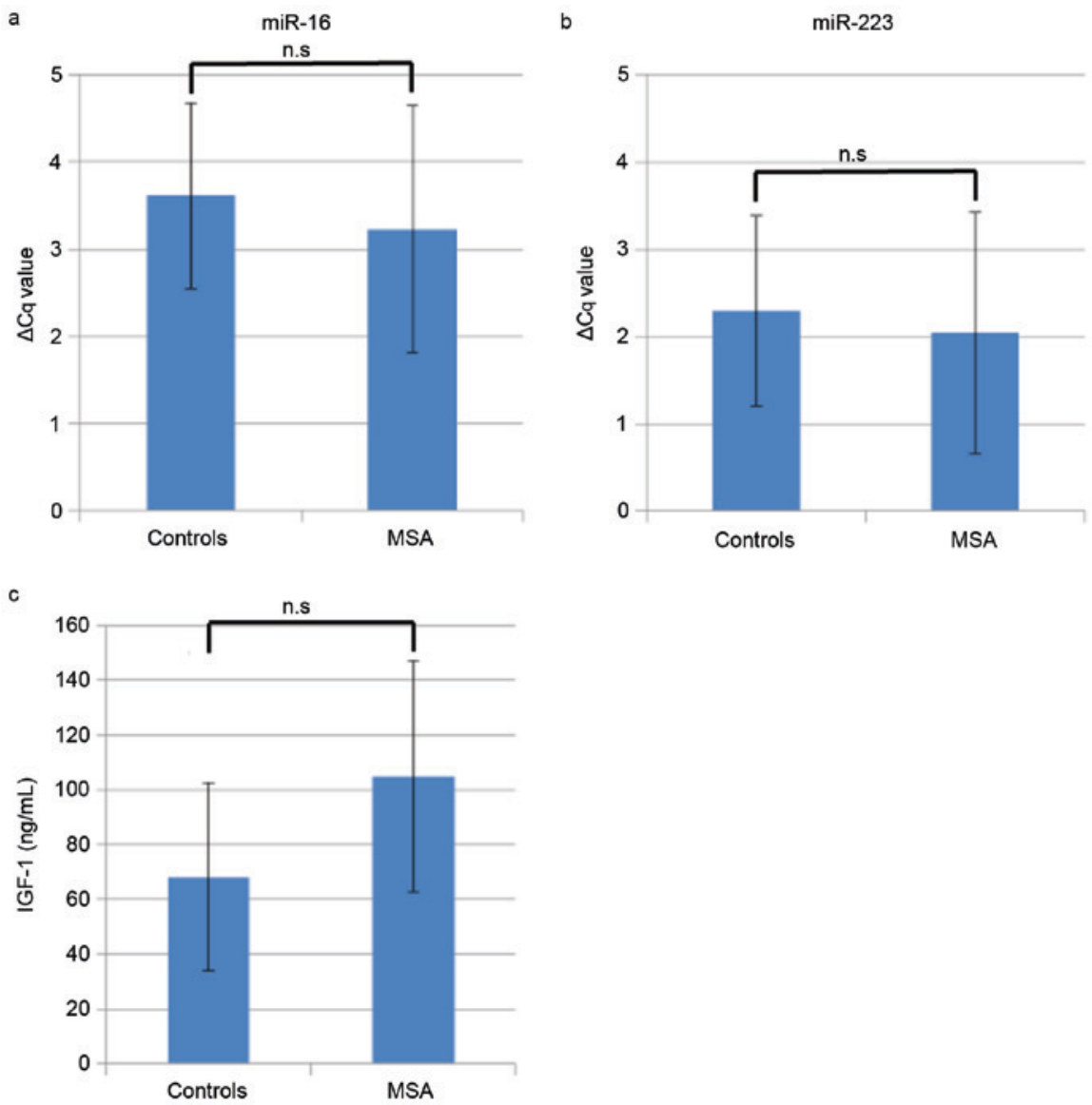

Figure 4. Expression levels of miR-16 and miR-223, and IGF-1 concentration in the serum of healthy controls and patients with MSA. Expression levels of (a) mir-16 and (b) mir-223 were compared between the controls and patients with MSA. (c) Serum IGF-1 concentration was compared between the controls and patients with MSA. Statistical significance was evaluated using unpaired Student's t-test. n.s, not significant; miR, microRNA; IGF-1, insulin-like growth factor-1; MSA, multiple system atrophy.

miR-24, miR-34b and miR-148b was observed in MSA when compared with PD. In studies investigating miRNA in the MSA brain, it was observed that miR-96 was upregulated in the frontal cortex (16) and miR-202 was upregulated in the cerebellum (15).
The results of the present study also identified that miR-24 and miR-223 were upregulated in MSA serum, as described previously (14). These results indicate that the methods used by the present study to determine the profile of miRNA are valid. However, the upregulation of miR-96 and miR-202 
described in these previous studies in MSA brain tissue was not observed in the present study. These differing results may be due to the differences between the brain tissue and serum samples used in each study.

A previous study demonstrated that the expression of several miRNAs was altered in a mouse model of pre-motor stage MSA (17) however, in the present study, this altered expression of miRNA was not observed. These differing results may be due to differences between mouse brain tissue and human serum.

miR-16 was the most elevated miRNA in the present study. The function of miR-16 has been primarily investigated in the field of oncology, and has been demonstrated to act as a tumor suppressor, an oncomiR (an miRNA associated with cancer), a modulator of the immune response and a negative regulator of angiogenesis (18). It has also been reported that miR-16 promotes $\alpha$-synuclein aggregation by downregulating heat shock protein 70 (HSP70) in a neuroblastoma cell line (19). A previous study of brain tissue with MSA identified that the dysfunction of HSP70 may contribute to neuronal cell death (20). Therefore, the elevation of miR-16 in the serum of patients with MSA may cause an accumulation of $\alpha$-synuclein via the downregulation of HSP70, which may be associated with the pathogenesis of MSA.

Previous studies have demonstrated that miR-24 (21), and the other upregulated miRNAs identified in the present study [miR-17 (22), miR-20a (23,24), miR-25 (25), miR-30d $(26,27)$ and miR-451 (28)], are associated with autophagy. These miRNAs serve a role in inhibiting autophagy, downregulating the expression of target genes (Table IV). In brain tissue with MSA, an impairment of autophagy has been observed (29). These miRNAs may decrease the level of autophagy-associated protein and induce the impairment of autophagy in patients with MSA.

In agreement with a previous study, miR-223 was also upregulated in the present study (14). It has been demonstrated that upregulation of miR-223 is associated with the pathophysiology of infection, inflammation and cancer (30). An in vitro study indicated that miR-223 downregulated the IGF-1 receptor and inhibited cell proliferation (10). In addition, the serum IGF-1 level increased in patients with MSA and is associated with disease progression (9). Therefore, an upregulation of miR-223 expression may contribute to the inhibition of IGF-1 signaling and thus induce cell death. Elevated IGF-1 levels in patients with MSA may be a compensatory response to upregulated miR-223. The present study assessed serum IGF-1 levels by the immune radio metric assay and serum miR-223 levels were measured by RT-qPCR. However, there were no significant differences observed between the IGF-1 and miR-223 levels in patients with MSA and the healthy controls in the present study; these results may be due to the small sample size.

The present study also observed that members of the let-7 family were upregulated in the serum of patients with MSA. The human let-7 family, which contains 13 members, is widely recognized as a class of miRNAs that have a tumor-suppressing effect (31). A previous study demonstrated that extracellular let-7b induced neurodegeneration through the neuronal toll-like receptor 7 and that the levels of cerebrospinal fluid let-7b expression in patients with Alzheimer's disease were higher than those observed in the healthy control subjects (32). Similarly, let-7 family members, including let-7b, may induce neurodegeneration in patients with MSA.

Using a microarray platform, the present study identified 22 upregulated miRNAs and 17 downregulated miRNAs in the serum of patients with MSA-P. The hierarchical clustering analysis observed marked differences in the miRNA profiles between the MSA and control groups. These alterations in the expression of miRNA may explain the differences between the pathophysiology of patients with MSA-P and MSA-C.

The present study had a number of limitations. The sample size was small and no validation of the level of miRNA expression was performed. In future investigations, a greater number of patients with MSA should be examined and individual miRNA expression levels should be determined by RT-qPCR. In addition, the present study analyzed serum miRNA, not cerebrospinal fluid (CSF) miRNA, the latter of which may be more appropriate for investigating neurodegenerative disorders such as MSA. However, analyses of miRNA expression in the serum of individuals with MSA may be more suitable, as obtaining serum samples is easier than collecting CSF samples.

In conclusion, the present study identified dysregulated miRNAs in the serum of patients with MSA. These miRNAs may serve as effective biomarkers for MSA and contribute to the pathogenesis of MSA, which may involve the accumulation of $\alpha$-synuclein and the suppression of autophagy.

\section{References}

1. Stefanova N, Bücke P, Duerr S and Wenning GK: Multiple system atrophy: An update. Lancet Neurol 8: 1172-1178, 2009.

2. Joutsa J, Gardberg M, Röyttä M and Kaasinen V: Diagnostic accuracy of parkinsonism syndromes by general neurologists. Parkinsonism Relat Disord 20: 840-844, 2014.

3. Jellinger KA: Neuropathology of multiple system atrophy: New thoughts about pathogenesis. Mov Disord 29: 1720-1741, 2014.

4. Stefanova N, Kaufmann WA, Humpel C, Poewe W and Wenning GK: Systemic proteasome inhibition triggers neurodegeneration in a transgenic mouse model expressing human $\alpha$-synuclein under oligodendrocyte promoter: Implications for multiple system atrophy. Acta Neuropathol 124: 51-65, 2012.

5. Bartel DP: MicroRNAs: Target recognition and regulatory functions. Cell 136: 215-233, 2009.

6. Salta E and De Strooper B: Non-coding RNAs with essential roles in neurodegenerative disorders. Lancet Neurol 11: 189-200, 2012.

7. Cloutier F, Marrero A, O'Connell C and Morin P Jr: MicroRNAs as potential circulating biomarkers for amyotrophic lateral sclerosis. J Mol Neurosci 56: 102-112, 2015.

8. Pellecchia MT, Pivonello R, Longo K, Manfredi M, Tessitore A, Amboni M, Pivonello C, Rocco M, Cozzolino A, Colao A and Barone P: Multiple system atrophy is associated with changes in peripheral insulin-like growth factor system. Mov Disord 25: 2621-2626, 2010.

9. Numao A, Suzuki K, Miyamoto M, Miyamoto T and Hirata K: Clinical correlates of serum insulin-like growth factor-1 in patients with Parkinson's disease, multiple system atrophy and progressive supranuclear palsy. Parkinsonism Relat Disord 20: 212-216, 2014.

10. Jia CY, Li HH, Zhu XC, Dong YW, Fu D, Zhao QL, Wu W and Wu XZ: MiR-223 suppresses cell proliferation by targeting IGF-1R. PLoS One 6: e27008, 2011.

11. Zhu S, Peng W, Li X, Weng J, Zhang X, Guo J, Huang D, Rong Q and Chen S: miR-1827 inhibits osteogenic differentiation by targeting IGF1 in MSMSCs. Sci Rep 7: 46136, 2017.

12. Gilman S, Wenning GK, Low PA, Brooks DJ, Mathias CJ, Trojanowski JQ, Wood NW, Colosimo C, Dürr A, Fowler CJ, et al: Second consensus statement on the diagnosis of multiple system atrophy. Neurology 71: 670-676, 2008. 
13. Livak KJ and Schmittgen TD: Analysis of relative gene expression data using real-time quantitative PCR and the 2(-Delta Delta C(T)) method. Methods 25: 402-408, 2001.

14. Vallelunga A, Ragusa M, Di Mauro S, Iannitti T, Pilleri M, Biundo R, Weis L, Di Pietro C, De Iuliis A, Nicoletti A, et al: Identification of circulating microRNAs for the differential diagnosis of Parkinson's disease and multiple system atrophy. Front Cell Neurosci 8: 156, 2014.

15. Lee ST, Chu K, Jung KH, Ban JJ, Im WS, Jo HY, Park JH, Lim JY, Shin JW, Moon J, et al: Altered expression of miR-202 in cerebellum of multiple-system atrophy. Mol Neurobiol 51: 180-186, 2015.

16. Ubhi K, Rockenstein E, Kragh C, Inglis C, Spencer B, Michael S, Mante M, Adame A, Galasko D and Masliah E: Widespread microRNA dysregulation in multiple system atrophy-disease-related alteration in miR-96. Eur J Neurosci 39: 1026-1041, 2014

17. Schafferer S, Khurana R, Refolo V, Venezia S, Sturm E, Piatti P, Hechenberger C, Hackl H, Kessler R, Willi M, et al: Changes in the miRNA-mRNA regulatory network precede motor symptoms in a mouse model of multiple system atrophy: Clinical implications. PLoS One 11: e0150705, 2016.

18. Huang E, Liu R and Chu Y: miRNA-15a/16: As tumor suppressors and more. Future Oncol 11: 2351-2363, 2015.

19. Zhang $Z$ and Cheng $Y$ : miR-16-1 promotes the aberrant $\alpha$-synuclein accumulation in Parkinson disease via targeting heat shock protein 70. ScientificWorldJournal 2014: 938348, 2014.

20. Kawamoto Y, Akiguchi I, Shirakashi Y, Honjo Y, Tomimoto H, Takahashi R and Budka H: Accumulation of Hsc70 and Hsp70 in glial cytoplasmic inclusions in patients with multiple system atrophy. Brain Res 1136: 219-227, 2007.

21. Pan B, Chen Y, Song H, Xu Y, Wang R and Chen L: Mir-24-3p downregulation contributes to VP16-DDP resistance in small-cell lung cancer by targeting ATG4A. Oncotarget 6: 317-331, 2015.

22. Comincini S, Allavena G, Palumbo S, Morini M, Durando F, Angeletti F, Pirtoli L and Miracco C: microRNA-17 regulates the expression of ATG7 and modulates the autophagy process, improving the sensitivity to temozolomide and low-dose ionizing radiation treatments in human glioblastoma cells. Cancer Biol Ther 14: 574-586, 2013.

23. Sun KT, Chen MY, Tu MG, Wang IK, Chang SS and Li CY: MicroRNA-20a regulates autophagy related protein-ATG16L1 in hypoxia-induced osteoclast differentiation. Bone 73: 145-153, 2015.
24. Wu H, Wang F, Hu S, Yin C, Li X, Zhao S, Wang J and Yan X: MiR-20a and miR-106b negatively regulate autophagy induced by leucine deprivation via suppression of ULK1 expression in C2C12 myoblasts. Cell Signal 24: 2179-2186, 2012.

25. Wang Z, Wang N, Liu P, Chen Q, Situ H, Xie T, Zhang J, Peng C, Lin Y and Chen J: MicroRNA-25 regulates chemoresistance-associated autophagy in breast cancer cells, a process modulated by the natural autophagy inducer isoliquiritigenin. Oncotarget 5: 7013-7026, 2014

26. Yang X, Zhong X, Tanyi JL, Shen J, Xu C, Gao P, Zheng TM, DeMichele A and Zhang L: mir-30d regulates multiple genes in the autophagy pathway and impairs autophagy process in human cancer cells. Biochem Biophys Res Commun 431: 617-622, 2013.

27. Zhang Y, Yang WQ, Zhu H, Qian YY, Zhou L, Ren YJ, Ren XC, Zhang L, Liu XP, Liu CG, et al: Regulation of autophagy by miR-30d impacts sensitivity of anaplastic thyroid carcinoma to cisplatin. Biochem Pharmacol 87: 562-570, 2014.

28. Song L, Su M, Wang S, Zou Y, Wang X, Wang Y, Cui H, Zhao P, Hui R and Wang J: MiR-451 is decreased in hypertrophic cardiomyopathy and regulates autophagy by targeting TSC1. J Cell Mol Med 18: 2266-2274, 2014.

29. Tanji K, Odagiri S, Maruyama A, Mori F, Kakita A, Takahashi H and Wakabayashi K: Alteration of autophagosomal proteins in the brain of multiple system atrophy. Neurobiol Dis 49: 190-198, 2013.

30. Haneklaus M, Gerlic M, O'Neill LA and Masters SL: miR-223: Infection, inflammation and cancer. J Intern Med 274: 215-226, 2013.

31. Boyerinas B, Park SM, Hau A, Murmann AE and Peter ME: The role of let-7 in cell differentiation and cancer. Endocr Relat Cancer 17: F19-F36, 2010.

32. Lehmann SM, Krüger C, Park B, Derkow K, Rosenberger K, Baumgart J, Trimbuch T, Eom G, Hinz M, Kaul D, et al: An unconventional role for miRNA: Let-7 activates Toll-like receptor 7 and causes neurodegeneration. Nat Neurosci 15: 827-835, 2012.

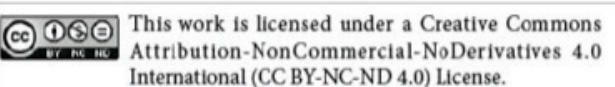
Attribution-NonCommercial-NoDerivatives 4.0 International (CC BY-NC-ND 4.0) License. 